\title{
recildunds
}

Revista Cientifica Mundo de la Investigación y el Conocimiento

\author{
Jessica María Castro Sánchez a ; Margareth Lisbeth Sánchez Castro 후 Cristina \\ Estefanía Colcha González ${ }^{\mathrm{c}}$
}

Derrame pericárdico diagnóstico y tratamiento

Pericardial effusion diagnosis and treatment

Revista Científica Mundo de la Investigación y el Conocimiento. Vol. 3 núm. 4., diciembre, ISSN: 2588-073X, 2019, pp. 233-255

DOI: $10.26820 /$ recimundo/3.(4).diciembre.2019.233-255

URL: http://recimundo.com/index.php/es/article/view/661

Código UNESCO: 3205 Medicina Interna

Tipo de Investigación: Artículo de Revisión

(C) RECIMUNDO; Editorial Saberes del Conocimiento, 2019

Recibido: 15/09/2019

Aceptado: 23/11/2019

Publicado: 30/12/2019

Correspondencia: jekita85_22@hotmail.com

a. Médico; Investigador Independiente; Guayaquil, Ecuador; jekita85_22@hotmail.com

b. Médico; Investigador Independiente; Guayaquil, Ecuador; marlis261991@ gmail.com

c. Médico; Investigador Independiente; Guayaquil, Ecuador; kittycristy90@ hotmail.com 


\section{Derrame pericárdico diagnóstico y tratamiento}

Vol. 3, núm. 4., (2019)

Jessica María Castro Sánchez; Margareth Lisbeth Sánchez Castro; Cristina Estefanía Colcha González

\section{RESUMEN}

El derrame pericárdico es la principal complicación de la pericarditis, la cual puede generar graves consecuencias dependiendo de la velocidad de instauración como de su etiología. Las principales causas reportadas son las neoplásicas y las idiopáticas, sin embargo, la etiología viral es subestimada debido a la dificultad de confirmar el diagnóstico. En casos de derrame pericárdico significativo la pericardiocentesis ha mostrado ser un procedimiento eficaz y seguro. Se realizó pericardiocentesis e instalación de catéter pigtail dando salida a $500 \mathrm{~mL}$ de líquido pericárdico serohemático. Frente a un paciente que se presenta con derrame pericárdico, el primer desafío es identificar su etiología. Un amplia variedad de agentes etiológicos puede ser responsable de los derrames pericárdicos, puesto que todos los agentes conocidos de enfermedad pericárdica pueden ser agentes causativos. Entre las causas más comunes se incluyen las infecciones (viral, bacteriana, tuberculosis), cáncer, insuficiencia cardíaca, enfermedades del tejido conectivo, lesión pericárdica (derrame posinfarto, síndromes pospericardiotomía, pericarditis postraumática), causas metabólicas (insuficiencia renal, hipotiroidismo, hipoalbuminemia), enfermedad miopericardítica, síndromes aórticos agudos secundarios a uso de determinados fármacos (p. ej., minoxidil). La frecuencia de las distintas etiologías es diferente según las series analizadas, la epidemiología local y el protocolo diagnóstico usado. En una serie derivada de un centro hospitalario se observó la presencia de derrame pericárdico en el $50 \%$ de los pacientes con pericarditis aguda viral o idiopática. El manejo clínico en este tipo de casos se realiza con base en la administración de antiinflamatorios no esteroideos (AINE) debido a su efectividad, tolerancia y menores efectos adversos. También, son usados fármacos como la aspirina, los diuréticos y la colchicina, el cual es un antiinflamatorio eficaz, que, además, produce alivio del dolor; sin embargo, no debe usarse en pacientes embarazadas. Asimismo, se recomienda el uso de corticoides, especialmente cuando el derrame pericárdico se asocia a inflamación sistémica.

Palabras Claves: Derrame Pericárdico; Periocardiocentenesis; Infecciones Virales; Infecciones Bacterianas; Complicaciones Médicas. 


\title{
Derrame pericárdico diagnóstico y tratamiento
}

Vol. 3, núm. 4., (2019)

Jessica María Castro Sánchez; Margareth Lisbeth Sánchez Castro; Cristina Estefanía Colcha

González

\begin{abstract}
Pericardial effusion is the main complication of pericarditis, which can cause serious consequences depending on the speed of establishment and its etiology. The main causes reported are neoplastic and idiopathic, however, the viral etiology is underestimated due to the difficulty of confirming the diagnosis. In cases of significant pericardial effusion, pericardiocentesis has proven to be an effective and safe procedure. Pericardiocentesis and pigtail catheter installation were performed, giving $500 \mathrm{~mL}$ of serohematic pericardial fluid. In front of a patient who presents with pericardial effusion, the first challenge is to identify its etiology. A wide variety of etiologic agents may be responsible for pericardial effusions, since all known pericardial disease agents can be causative agents. Common causes include infections (viral, bacterial, tuberculosis), cancer, heart failure, connective tissue diseases, pericardial lesion (post-infarction effusion, postpericardiotomy syndromes, post-traumatic pericarditis), metabolic causes (renal insufficiency, hypothyroidism, hypoalbuminemia), myopericarditic disease, acute aortic syndromes secondary to the use of certain drugs (eg, minoxidil). The frequency of the different etiologies is different according to the series analyzed, the local epidemiology and the diagnostic protocol used. In a series derived from a hospital, the presence of pericardial effusion was observed in $50 \%$ of patients with acute viral or idiopathic pericarditis. Clinical management in these types of cases is based on the administration of non-steroidal anti-inflammatory drugs (NSAIDs) due to their effectiveness, tolerance and lower adverse effects. Also, drugs such as aspirin, diuretics and colchicine are used, which is an effective anti-inflammatory, which also produces pain relief; however, it should not be used in pregnant patients. Also, the use of corticosteroids is recommended, especially when pericardial effusion is associated with systemic inflammation.
\end{abstract}

Keywords: Pericardial effusion; Periocardiocentenesis; Viral Infections; Bacterial Infections; Medical Complications. 


\section{Derrame pericárdico diagnóstico y tratamiento}

Vol. 3, núm. 4., (2019)

Jessica María Castro Sánchez; Margareth Lisbeth Sánchez Castro; Cristina Estefanía Colcha González

\section{Introducción.}

El pericardio representa un doble saco membranoso, fibroso y seroso que envuelve al corazón y al origen de los grandes vasos. Está compuesta por una capa interna o visceral serosa y una capa externa o parietal fibrosa El espacio pericardio está localizado entre la capa parietal y visceral. Normalmente contiene entre 5 a $20 \mathrm{ml}$ de fluido claro que actúa como lubricante permitiendo el movimiento libre del corazón dentro del saco pericárdico. (Keanne, 2017). La inflamación (pericarditis) o lesión del espacio pericárdico que presenta algún paciente puede ser agudo o crónico. Se observa precoz en la evolución de infarto miocárdico, cirugía cardíaca y trauma cerrado o penetrante. Otras causas incluyen reacción inmunológica autoinmune o en respuesta a infección viral previa.

Una de las complicaciones más frecuentes y es secundario a una pericarditis es el Derrame Pericárdico (DP). Este es particularmente importante cuando existe acumulación de líquido en forma súbita produciendo taponamiento cardíaco. (Russ, 2016). Dependiendo del tamaño del paciente, cantidades tan pequeñas de líquido como $20 \mathrm{mi}$, acumulado en minutos u horas puede causar taponamiento, mientras que derrames subagudos y crónicos tan significativos como 1 a 2 litros pueden ser muy bien tolerados en niños mayores y adultos.

El DP puede ser secundario a infecciones, falla cardíaca congestiva, estado post cirugía de Fontan, Síndrome post pericardiotomía y algunas enfermedades neoplásicas. El derrame pericárdico se define como la presencia de líquido en el espacio pericárdico superior a la normal (15-50 mi o $\mathrm{lml} / \mathrm{kg}$ ) secundario a una pericarditis. (Russ, 2016). Su origen puede deberse a una amplia variedad de situaciones clínicas tales como infecciones virales, bacterianas, fúngicas, o 


\section{Derrame pericárdico diagnóstico y tratamiento}

Vol. 3, núm. 4., (2019)

Jessica María Castro Sánchez; Margareth Lisbeth Sánchez Castro; Cristina Estefanía Colcha

González

como resultado de procesos inflamatorios, autoinmunes, neoplásicos y dentro de la evolución postoperatorio de la cirugía cardíaca Hace 40 años atrás, la fiebre reumática y la pericarditis bacteriana fueron las etiologías más comunes:

Con la introducción de las terapias antibióticas y nuevas vacunas, en especial contra $H$. influenzae, las causas bacterianas han disminuido considerablemente. Actualmente, la frecuencia de las causas de derrame pericárdico depende de la población y lugar geográfico en que se haya estudiado Publicaciones recientes señalan que las causas más comunes serías las neoplásicas y las idio-páticas (Russ, 2016). Sin embargo, la etiología viral todavía es una causa común en ciertos reportes $^{5}$, la cual es subestimada debido a la dificultad de confirmar el diagnóstico. La técnica de reacción de polimerasa en cadena (PCR) es una herramienta diagnostica que permite identificar la etiología viral específica En pacientes VIH positivo es más común la pericarditis tuberculosa

\section{Imagen $\mathbf{N}^{\circ}$ 1. Derrame Pericárdico}

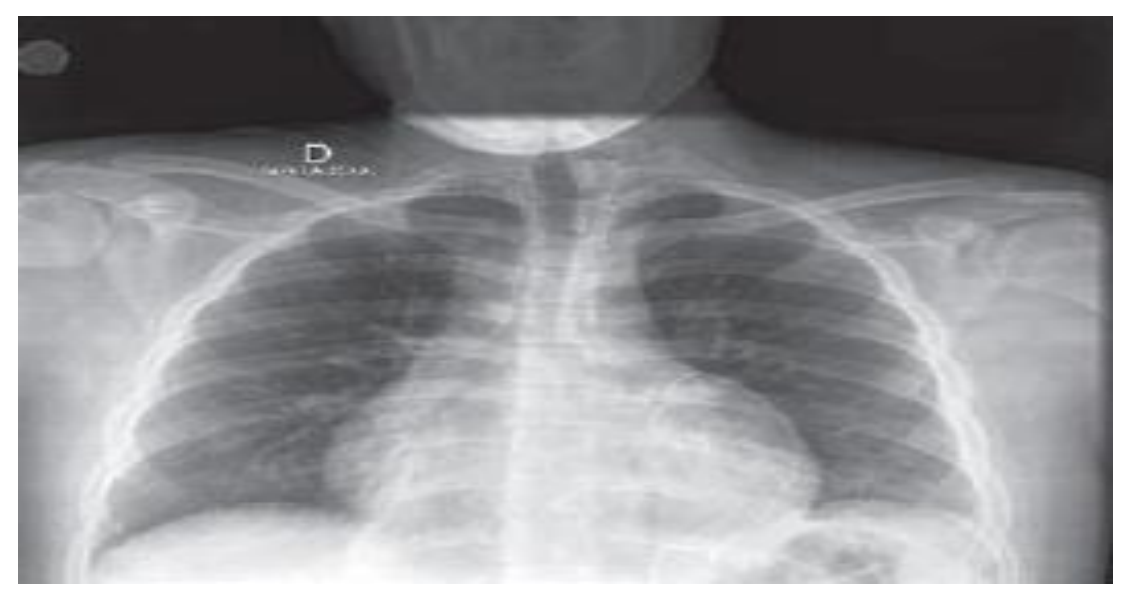

Fuente: (Russ, 2016). 


\section{Derrame pericárdico diagnóstico y tratamiento}

Vol. 3, núm. 4., (2019)

Jessica María Castro Sánchez; Margareth Lisbeth Sánchez Castro; Cristina Estefanía Colcha González

Es importante señalar que, el derrame pericárdico es la principal complicación de la pericarditis, además es un hallazgo muy común en la práctica clínica diaria. En algunas ocasiones, el derrame pericárdico puede ser fácilmente relacionado con una enfermedad subyacente, pero otras requieren una evaluación específica para determinar su etiología. (Russ, 2016). Las principales causas reportadas son las neoplásicas y las idiopáticas. El tratamiento médico del derrame pericárdico está guiado por la presencia de signos inflamatorios y por la enfermedad subyacente, si es que hay alguna presente. El drenaje del líquido pericárdico es mandatorio cuando se está en presencia de un taponamiento cardiaco

Asimismo, las enfermedades del pericardio son relativamente comunes en la práctica clínica, por tanto, son una causa frecuente de consulta e ingreso a los servicios de cardiología. En cuanto al derrame pericárdico, es una patología ocasionada por diversos factores etiológicos, la cual se manifiesta con síntomas como disnea de esfuerzo que luego progresa a ortopnea, taquicardia, hipotensión, además de dolor torácico y sensación de plenitud, entre otros síntomas inflamatorios. (Russ, 2016). Su tratamiento debe estar enfocado a resolver la etiología y al manejo de los síntomas; no obstante, en situaciones en las que el diagnóstico es impreciso o es idiopático, y ante signos y elevación de marcadores inflamatorios, el manejo clínico debe ser igual al de la pericarditis.

Aunque en la práctica clínica el tratamiento del derrame pericárdico no severo se hace con base en la administración de AINE; en la actualidad han surgido avances importantes en el tratamiento de estas enfermedades; un ejemplo de ello es la indicación de colchicina como fármaco de primera elección, el cual unido a la terapia convencional reduce las tasas de recurrencias; generando así la necesidad de investigar la mejor estrategia terapéutica disponible 


\section{Derrame pericárdico diagnóstico y tratamiento}

Vol. 3, núm. 4., (2019)

Jessica María Castro Sánchez; Margareth Lisbeth Sánchez Castro; Cristina Estefanía Colcha

González

con base en evidencia científica actualizada; pese a ello, aún persisten algunas limitaciones en cuanto a la difusión de estudios con rigurosidad adecuada y calidad metodológica, debido al acceso restringido de algunas bases de datos y la disponibilidad reducida de tiempo de los profesionales de la salud. (Russ, 2016).

La presentación clínica del derrame pericárdico depende fundamentalmente de la velocidad de instalación y la etiología del derrame, muchas veces con síntomas que pueden estar relacionados con la enfermedad causal. La tasa de acumulación del líquido es crítica para la presentación clínica. Si es rápida, como en aquella posterior a traumatismo o perforación iatrogénica, la evolución es dramática y tan solo pequeños montos de sangre son responsables del rápido aumento en la presión intrapericárdica con desarrollo de taponamiento cardíaco en minutos u horas. (Maischa, 2017). Por el contrario, una lenta acumulación de líquido pericárdico permite el desarrollo de un gran derrame en días a semanas antes de provocar un significativo incremento en la presión intrapericárdica que derive en signos y síntomas.

El derrame pericárdico puede ser asintomático o dar síntomas inespecíficos que pueden incluir disnea durante el ejercicio con progresión a ortopnea, dolor torácico o sensación de plenitud o ambos. Ocasionalmente los síntomas pueden ser provocados por compresión local e incluyen náuseas, disfagia, ronquera e hipo por compromiso del nervio frénico. También, pueden ocurrir otros síntomas como fiebre, tos, debilidad, fatiga, anorexia, escalofríos y palpitaciones que reflejan el carácter compresivo del líquido pericárdico sobre estructuras anatómicas contiguas, o están relacionados con la enfermedad causal. (Maischa, 2017). Muchos pacientes con un gran derrame pericárdico (más de $20 \mathrm{~mm}$ por ecocardiografía), crónico (mayor de 3 meses) e idiopático pueden estar asintomáticos y permanecer clínicamente estables por muchos 


\section{Derrame pericárdico diagnóstico y tratamiento}

Vol. 3, núm. 4., (2019)

Jessica María Castro Sánchez; Margareth Lisbeth Sánchez Castro; Cristina Estefanía Colcha González

años. Sin embargo, esta condición puede derivar en el desarrollo de taponamiento cardíaco en hasta el $29 \%$ de las personas afectadas con esta patología.

Sus manifestaciones clínicas se asocian con el gatillo del taponamiento, el cual es desconocido, pero la hipovolemia, las taquiarritmias paroxísticas o una pericarditis aguda recurrente lo precipitarían. El examen físico en pacientes con derrame pericárdico puede ser normal. En algunas ocasiones, por aumento de la presión intrapericárdica y la presencia de un gran volumen de líquido, puede observarse la distensión de las venas del cuello con aumento de la presión venosa yugular y disminución de los ruidos cardíacos durante la auscultación. (Maischa, 2017). No es usual el hallazgo del frote por fricción pericárdica; sin embargo, no existe una precisa correlación entre este hallazgo y la presencia o el tamaño del derrame; de allí, la importancia informativa que tiene el presente artículo, el cual tiene como propósito describir el manejo del derrame pericárdico.

\section{Fuentes documentales}

El análisis correspondiente a las características que predomina en el tema seleccionado, llevan a incluir diferentes fuentes documentales encargadas de darle el respectivo apoyo y en ese sentido cumplir con la valoración de los hechos a fin de generar nuevos criterios que sirven de referencia a otros procesos investigativos. Para (Arias, 2010), las fuentes documentales incorporadas en la investigación documental o bibliográfica, "representa la suma de materiales sistemáticos que son revisados en forma rigurosa y profunda para llegar a un análisis del fenómeno". (p.41). Por lo tanto, se procedió a cumplir con la realización de una lectura previa determinada por encontrar aquellos aspectos estrechamente vinculados con el “MANEJO DE 


\section{Derrame pericárdico diagnóstico y tratamiento}

Vol. 3, núm. 4., (2019)

Jessica María Castro Sánchez; Margareth Lisbeth Sánchez Castro; Cristina Estefanía Colcha

González

DERRAME PERICÁRDICO” para luego explicar mediante un desarrollo las respectivas apreciaciones generales de importancia.

\section{Técnicas para la Recolección de la Información}

La conducción de la investigación para ser realizada en función a las particularidades que determinan a los estudios documentales tiene como fin el desarrollo de un conjunto de acciones encargadas de llevar a la selección de técnicas estrechamente vinculadas con las características del estudio. En tal sentido, (Arias Ob cit) refiere, que es "una técnica particular para aportar ayuda a los procedimientos de selección de las ideas primarias y secundarias". (p. 71).

Por ello, se procedió a la utilización del subrayado, resúmenes, fichaje, como parte básica para la revisión y selección de los documentos que presentan el contenido teórico. Es decir, que mediante su aplicación de estas técnicas se pudo llegar a recoger informaciones en cuanto a la revisión bibliográfica de los diversos elementos encargados de orientar el proceso de investigación. Tal como lo expresa, (Arias Ob cit) "las técnicas documentales proporcionan las herramientas esenciales y determinantes para responder a los objetivos formulados y llegar a resultados efectivos" (p. 58). Es decir, para responder con eficiencia a las necesidades investigativas, se introdujeron como técnica de recolección el método inductivo, que hizo posible llevar a cabo una valoración de los hechos de forma particular para llegar a la explicación desde una visión general.

Asimismo, se emplearon las técnicas de análisis de información para la realización de la investigación que fue ejecutada bajo la dinámica de aplicar diversos elementos encargados de determinar el camino a recorrer por el estudio, según, (Arias, Ob cit) las técnicas de 


\section{Derrame pericárdico diagnóstico y tratamiento}

Vol. 3, núm. 4., (2019)

Jessica María Castro Sánchez; Margareth Lisbeth Sánchez Castro; Cristina Estefanía Colcha González

procesamiento de datos en los estudios documentales "son las encargadas de ofrecer al investigador la visión o pasos que debe cumplir durante su ejercicio, cada una de ellas debe estar en correspondencia con el nivel a emplear" (p. 123). Esto indica, que para llevar a cabo el procesamiento de los datos obtenidos, es necesario establecer las técnicas que serán seleccionadas, destacándose en este caso, de manera particular: fichas de resumen, textual, registros descriptivos entre otros, los mismos se deben ajustar al nivel que ha sido seleccionado.

\section{Resultados.}

\section{Pericarditis Aguda}

El diagnóstico de pericarditis aguda requiere que se cumplan al menos de 2 de los siguientes criterios: dolor torácico típico (agudo y pleurítico que mejora con la posición sentada o inclinada hacia adelante), frote pericárdico, cambios electrocardiográficos sugestivos (elevación difusa del segmento ST o depresión del segmento PR) y la presencia de derrame pericárdico nuevo o empeoramiento de un derrame previo. (Maischa, 2017). El nombre de Miopericarditis aguda se le llama al cuadro clínico definido de pericarditis aguda con elevación de marcadores de necrosis miocárdica (TnI o T o CPK-MB) sin compromiso focal o global de la función contráctil del ventrículo izquierdo evaluado por ecocardiograma Doppler o RM. Por su parte, la Perimiocarditis aguda es definida como aquel cuadro de pericarditis aguda con elevación de marcadores de necrosis miocárdica (TnI o T o CPK-MB) con compromiso focal o global de la función contráctil del ventrículo izquierdo evaluado por ecocardiograma Doppler o RM. 


\section{Derrame pericárdico diagnóstico y tratamiento}

Vol. 3, núm. 4., (2019)

Jessica María Castro Sánchez; Margareth Lisbeth Sánchez Castro; Cristina Estefanía Colcha

González

- Pericarditis recurrente: documentación de un primer ataque de pericarditis, seguido de un período de al menos 4-6 semanas libre de síntomas y la ocurrencia de un nuevo cuadro de pericarditis.

- Pericarditis incesante: caracterizada por tener con una duración mayor de 4 a 6 semanas y menor de 3 meses sin remisión.

- Pericarditis crónica: la que dura más de 3 meses. A su vez, las pericarditis pueden ser secas, fibrinosas o efusivas, independientemente de su etiología. (Maischa, 2017).

Tal y como es señalado, la pericarditis aguda representa un síndrome clínico cuyo diagnóstico está basado en criterios simples no siempre informados de manera clara e incluye el dolor torácico (característico), el frote pericárdico, alteraciones electrocardiográficas evolutivas (elevación difusa del segmento ST en el electrocardiograma [ECG]) y derrame pericárdico. Al menos 2 de 4 factores deberían estar presentes para el diagnóstico de pericarditis aguda, aunque la auscultación de un frote pericárdico permite, por sí solo, establecerlo. (Fournier, 2017). Por todo esto, la inclusión del derrame pericárdico no es totalmente aceptada por algunos autores, la misma está justificada en la medida en que, si bien no es necesaria para el diagnóstico, su hallazgo es confirmatorio en un paciente con un cuadro clínico sugestivo.

Conforme a esto, se logra comprender que la forma clásica de presentación es la de un cuadro sintomático agudo, pero también puede presentarse en forma subaguda o crónica. Son comunes la presencia de fiebre (habitualmente $<39{ }^{\circ} \mathrm{C}$ ), molestia, malestar y mialgias como pródromos. (Fournier, 2017). Los pacientes añosos pueden no tener fiebre. En cuanto al dolor precordial, suele presentarse como retroesternal o en hemitórax izquierdo, tipo agudo, cortante o 


\section{Derrame pericárdico diagnóstico y tratamiento}

Vol. 3, núm. 4., (2019)

Jessica María Castro Sánchez; Margareth Lisbeth Sánchez Castro; Cristina Estefanía Colcha González

punzante, y puede irradiarse en forma similar a la angina de pecho e incluso tener características similares al ángor o características pleuríticas. El dolor generalmente se modifica con los cambios posturales y en ocasiones está asociado a tos no productiva y disnea.

Tabla $\mathbf{N}^{\circ}$ 1. Recomendaciones para el diagnóstico de la Pericarditis

\begin{tabular}{|c|c|c|}
\hline Recomendación & Clase & $\begin{array}{l}\text { Nivel de } \\
\text { evidencia }\end{array}$ \\
\hline - La auscultación de un frote pericardico es altamente sugestiva de pericarditis aguda & 1 & B \\
\hline $\begin{array}{l}\text { - La presencia de elevación difusa del segmento ST evolutiva en el ECG es altamente sugestiva de } \\
\text { pericarditis aguda }\end{array}$ & 1 & B \\
\hline $\begin{array}{l}\text { - El dolor torácico caracteristico retroesternal que aumenta con la tos yla inspiración y a veces mejora } \\
\text { con la inclinación hacia adelante es altamente sugestivo de pericarditis aguda }\end{array}$ & 1 & B \\
\hline $\begin{array}{l}\text { - Los hallazgos de VSG acelerada, PCR aumentada, leucocitosis, aumento de troponinas y LDH pueden } \\
\text { orientar al diagnostico }\end{array}$ & 1 & B \\
\hline $\begin{array}{l}\text { - La aparicion o aumento de un derrame pericardico previo o signos de taponamiento en este contexto } \\
\text { es altamente sugestivo de pericarditis aguda }\end{array}$ & 1 & B \\
\hline $\begin{array}{l}\text { - La Rx de torax puede ser normal o presentar signos de derrame pericárdico o patologia mediastinal } \\
\text { o pulmonar }\end{array}$ & 1 & B \\
\hline
\end{tabular}

Fuente: (Fournier, 2017)

Asimismo, el frote pericárdico puede auscultarse en forma transitoria y tener una, dos o tres fases. Puede encontrarse derrame pleural asociado. Al mismo tiempo, la detección de marcadores de inflamación elevados (como proteína C reactiva; PCR) también es confirmatoria y debería considerarse como un elemento más para el diagnóstico y seguimiento de la pericarditis. (Stam, 2013). Por otro lado, se encuentra la eritrosedimentación (VSD), la cual es menos costosa pero también menos específica; los valores de PCR se elevan y disminuyen más tempranamente que la VSD, lo que los convierte en un mejor marcador para la monitorización, particularmente 


\section{Derrame pericárdico diagnóstico y tratamiento}

Vol. 3, núm. 4., (2019)

Jessica María Castro Sánchez; Margareth Lisbeth Sánchez Castro; Cristina Estefanía Colcha

González

en la medida en que es menos influenciable por otras situaciones clínicas (como por ejemplo anemia).

La evaluación diagnóstica básica debería incluir interrogatorio, auscultación, ECG, ecocardiografía transtorácica, análisis de sangre de rutina (incluyendo marcadores de inflamación como VSD y PCR y de lesión miocárdica (CPK-MB y troponinas), así como radiografía de tórax $(\mathrm{Rx})$ en todos los casos en que se sospeche el diagnóstico de pericarditis. (Stam, 2013). De allí, que autores han propuesto un protocolo de 3 pasos para el manejo diagnóstico de las enfermedades pericárdicas:

- Estadio I: incluye historia clínica, examen físico, ECG, radiografía de tórax, evaluación para tuberculosis, medición de anticuerpos antinucleares en suero y hormonas tiroideas, así como otros estudios sugeridos tras la evaluación inicial.

- Estadio II: incluye a la pericardiocentesis en pacientes con taponamiento cardíaco, sospecha de pericarditis purulenta o derrames pericárdicos crónicos voluminosos.

- Estadio III: incluye una biopsia quirúrgica del pericardio en pacientes con taponamiento persistente o recurrente luego de pericardiocentesis y cuando la permanencia del derrame es mayor de 3 semanas luego del ingreso en el hospital sin diagnóstico etiológico.

\section{Diagnóstico}

Si el médico tratante sospecha que el paciente tiene derrame pericárdico, realizará una serie de análisis para detectarlo, identificar las posibles causas y determinar el tratamiento (Stam, 2013) ; entre los mismos se encuentra: 


\section{Derrame pericárdico diagnóstico y tratamiento}

Vol. 3, núm. 4., (2019)

Jessica María Castro Sánchez; Margareth Lisbeth Sánchez Castro; Cristina Estefanía Colcha González

Examen médico: El médico realizará un examen médico, que implica escuchar el corazón del paciente con un estetoscopio.

Ecocardiograma: Un ecocardiograma usa ondas sonoras para crear imágenes del corazón en tiempo real. Con este procedimiento, un cardiólogo puede ver el tamaño del derrame pericárdico sobre la base de la cantidad de espacio que hay entre las dos capas del pericardio. Un ecocardiograma también puede mostrar la disminución de la función cardíaca debido a la presión que sufre el corazón (taponamiento). A través del ecocardiograma el cardiólogo podría ver si una o más cavidades del corazón han colapsado y el grado de eficacia con el que el corazón bombea sangre. Existen dos tipos de ecocardiogramas:

- Ecocardiograma transtorácico. Para esta prueba se utiliza un dispositivo que emite sonido (transductor) que se coloca en el pecho, sobre el corazón.

- Ecocardiograma transesofágico. Se introduce un transductor diminuto dentro de un tubo hacia dentro del tubo digestivo y va desde la garganta hasta el estómago (esófago). Dado que el esófago está cerca del corazón, colocar allí el transductor suele proporcionar una imagen más detallada del corazón.

Electrocardiograma: Un electrocardiograma, también conocido como ECG, registra señales eléctricas a medida que se desplazan por el corazón. El cardiólogo puede buscar patrones que sugieran la presencia de taponamiento.

Radiografía torácica: Esta puede mostrar una silueta del corazón dilatado si existe una gran cantidad de líquido en el pericardio. 


\section{Derrame pericárdico diagnóstico y tratamiento}

Vol. 3, núm. 4., (2019)

Jessica María Castro Sánchez; Margareth Lisbeth Sánchez Castro; Cristina Estefanía Colcha

González

Otras tecnologías de diagnóstico por imagen

La tomografía computarizada (TC) y la resonancia magnética (RM), las cuales son tecnologías de diagnóstico por imágenes que pueden detectar derrame pericárdico, aunque generalmente no se utilizan para este trastorno. Sin embargo, es posible diagnosticar derrame pericárdico cuando se realizan estas pruebas por otros motivos.

Otras pruebas: Si hay evidencia de derrame pericárdico, el médico podría solicitar análisis de sangre u otras pruebas de diagnóstico para identificar una causa. (Stam, 2013)

Tabla $\mathbf{N}^{\circ}$ 2. Características del paciente con Pericarditis

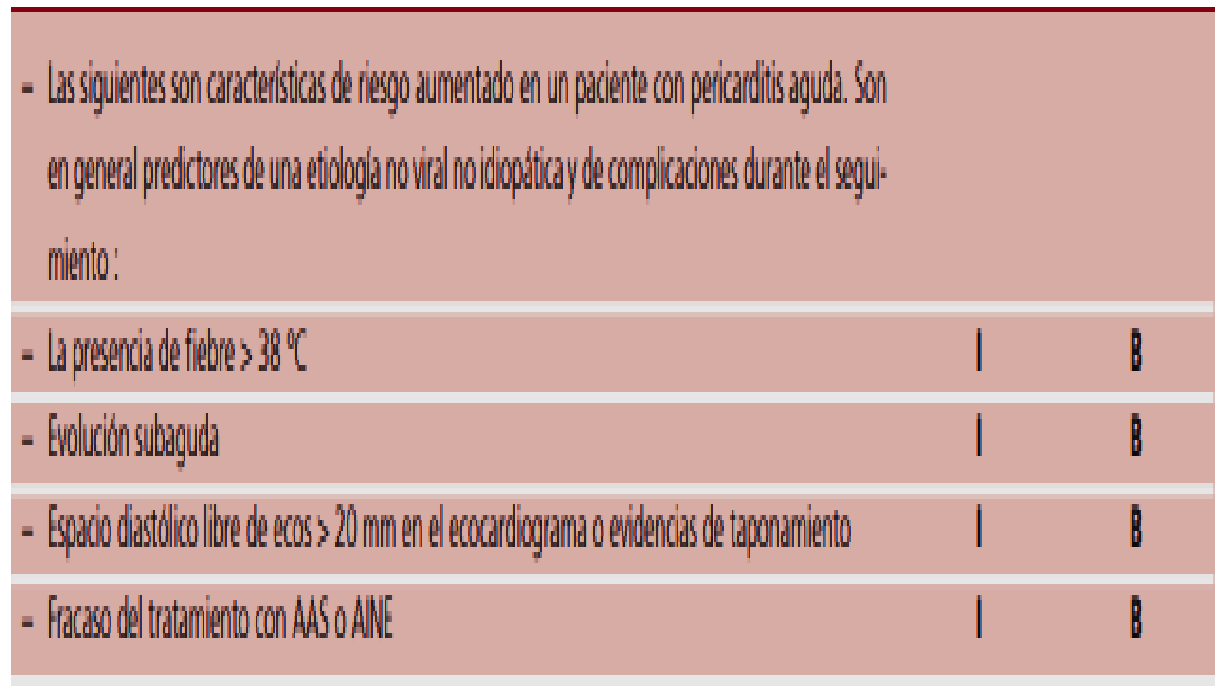

Fuente: (Stam, 2013)

\section{Tratamiento}

El manejo de las enfermedades pericárdicas en general y de la pericarditis aguda en particular se ha llevado a cabo en forma empírica a lo largo de años. Solo en los últimos 10 años, 


\section{Derrame pericárdico diagnóstico y tratamiento}

Vol. 3, núm. 4., (2019)

Jessica María Castro Sánchez; Margareth Lisbeth Sánchez Castro; Cristina Estefanía Colcha González

tras la publicación de una serie de ensayos clínicos aleatorizados, se han establecido las bases de su tratamiento racional, basados en evidencia objetiva. A diferencia de las otras enfermedades del corazón existen pocos estudios clínicos aleatorizados sobre las enfermedades del pericardio y los que existen incluyen escaso número de pacientes, por lo cual la mayoría de las indicaciones diagnósticas y terapéuticas se basan en niveles de evidencia clases B y C. (Stam, 2013)

Desde esta perspectiva se logra comprender que el tratamiento para el derrame pericárdico dependerá de la cantidad de líquido acumulado, de aquello que esté causando el derrame y de si el paciente tiene o presenta probabilidades de tener taponamiento cardíaco. Tratar la causa del derrame pericárdico suele corregir el problema.

Medicamentos que reducen la inflamación: Si el paciente no tienes un taponamiento y no existe una amenaza inmediata de que se produzca, el médico podría indicarte una de las siguientes opciones para tratar la inflamación del pericardio, la cual podría contribuir a un derrame pericárdico:

- Aspirina

- Medicamentos antiinflamatorios no esteroides (AINE), como indometacina (Indocin) o ibuprofeno (Advil, Motrin IB y otros)

- Conquicina (Colcrys)

- Corticoesteroides, como prednisona

Otros tratamientos: Si los tratamientos con antiinflamatorios no corrigen el problema y tienes una acumulación importante de líquido que genera síntomas y te hace más propenso a un 


\section{Derrame pericárdico diagnóstico y tratamiento}

Vol. 3, núm. 4., (2019)

Jessica María Castro Sánchez; Margareth Lisbeth Sánchez Castro; Cristina Estefanía Colcha

González

taponamiento, o si presentas taponamiento, tu cardiólogo probablemente recomiende uno de los siguientes procedimientos para drenar el líquido o evitar que este vuelva a acumularse.

- Drenar el líquido. El médico puede introducir una aguja en el espacio pericárdico y, luego, usar un tubo pequeño (catéter) para drenar el líquido: este procedimiento se llama pericardiocentesis.

El médico usará dispositivos para imágenes, ya sea ecocardiografía o una tecnología de radiografía llamada fluoroscopia - con el fin de guiar el trabajo. Un aparato de ECG controlará tu corazón durante el procedimiento. En la mayoría de los casos, el catéter se dejará en el lugar para drenar el espacio pericárdico durante algunos días, a fin de evitar que vuelva a acumularse líquido.

- Cirugía a corazón abierto. Si hay sangrado dentro del pericardio, especialmente debido a una cirugía cardíaca reciente $\mathrm{u}$ otras complicaciones, puede que te realicen una cirugía para drenar el pericardio y reparar el daño. Ocasionalmente, un cirujano podría drenar el pericardio y crear un «pasaje» que permita que drene cuando sea necesario a la cavidad abdominal, donde el líquido puede ser absorbido.

- Abrir las capas. La pericardiotomía con balón es un procedimiento que se realiza con poca frecuencia, mediante el cual se inserta un balón desinflado entre las capas del pericardio; luego, el balón se infla para estirar las capas.

- Extraer el pericardio. La extracción quirúrgica de la totalidad o una parte del pericardio (pericardiectomía) suele reservarse para el tratamiento de derrames pericárdicos que reaparecen a pesar del drenaje con catéter. (Stam, 2013) 


\section{Derrame pericárdico diagnóstico y tratamiento}

Vol. 3, núm. 4., (2019)

Jessica María Castro Sánchez; Margareth Lisbeth Sánchez Castro; Cristina Estefanía Colcha González

Tabla $\mathbf{N}^{\circ}$ 3. Indicadores de riesgo en pacientes con Pericarditis

- Los pacientes con pericarditis aguda y las siguientes caracteristicas deben ser intenados para su

mejor control y tratamienton

- Pacientes con caracteristicas de alto rimgo fliebres $38^{\circ}$ "C, evolucion subaguda, eqpacio diastolico

libre de ecos 20 minn o evidencas de tapomanimento cardlaco en el cocoardograma, fracaso con

AMSOANE)

Evidencias de componioniso del niocardo (miopericarditis)

B

Etiologla traumbtica o inmunosupresion o tratamiento anticoagulante conconitante

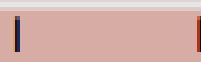

I

Fuente: (Stam, 2013)

Sobre la base de estos criterios se puede establecer a qué pacientes con pericarditis aguda es necesario internar; esto debido a que, ante la ausencia de estos predictores de mal pronóstico, los pacientes pueden considerarse como de bajo riesgo de responder a causas específicas y presentar complicaciones en su evolución, por lo que pueden manejarse en forma ambulatoria. En un estudio prospectivo de 300 pacientes consecutivos con pericarditis aguda, 254 pacientes (85\%) fueron de bajo riesgo y no fueron internados sino recibieron tratamiento empírico con aspirina (800 mg cada 6-8 horas durante 7-10 días), sin evaluación etiológica. (Stam, 2013)

El protocolo fue seguro (sin casos de taponamiento cardíaco) y costoefectivo: 230 de 254 casos de bajo riesgo $(90,6 \%)$ tuvieron un diagnóstico final de pericarditis viral o idiopática luego de un seguimiento de 38 meses. (Stam, 2013) El mismo protocolo fue también útil en pacientes con recurrencias que generalmente pueden ser tratados en forma ambulatoria a menos que presenten predictores de mal pronóstico y se descarte una causa específica. Con un diagnóstico 


\section{Derrame pericárdico diagnóstico y tratamiento}

Vol. 3, núm. 4., (2019)

Jessica María Castro Sánchez; Margareth Lisbeth Sánchez Castro; Cristina Estefanía Colcha

González

claro de origen idiopático, también es innecesario repetir una nueva valoración etiológica ante cada recurrencia a menos que se hagan evidentes nuevas características clínicas.

\section{Manejo de Derrame Pericárdico}

El procedimiento a realizarse en el derrame pericárdico se debe realizar bajo sedación, analgesia sistémica y anestesia local, con monitorización no invasiva continua, la cual debe incluir: monitorización electrocardiográfica, presión arterial, saturación transcutánea de oxígeno.

Previa técnica de asepsia, la piel y estructuras más profundas son infiltradas con lidocaina 1-2\%. Se inserta la aguja con Teflón en el sitio previamente definido y siguiendo una trayectoria predeterminada con orientación hacia el hombro izquierdo, aspirando en forma continua. (Penza, 2017) El ángulo usual por acceso subxifoideo es de 15 grados sobre la piel.

Si el líquido es obtenido, la vaina del Teflón se avanza cerca de $2 \mathrm{~cm}$ manteniendo fija la aguja y luego esta se remueve. Si el líquido obtenido es sanguinolento se debe confirmar la posición intrapericardica. Si esta es intrapericardico el líquido extraído no se coagula. Además se puede inyectar una pequeña cantidad de suero salino agitado como forma de obtener contraste para así verificar la posición por medio de la visión ecocardiográfica. (Penza, 2017). La opacificación densa del espacio pericárdico confirma la posición intrapericardica (contraste salino) con ausencia de contraste intracardíaco.

El derrame puede ser drenado con punción aspirativa única. Si se requiere drenaje prolongado se debe introducir por el Teflón una guía con punta blanda para evitar daño sobre el corazón y asegurar la ubicación en el espacio pericárdico y así luego introducir catéter tipo 


\section{Derrame pericárdico diagnóstico y tratamiento}

Vol. 3, núm. 4., (2019)

Jessica María Castro Sánchez; Margareth Lisbeth Sánchez Castro; Cristina Estefanía Colcha González

pigtail, utilizando técnica Seldinger. (Penza, 2017) Una vez que la guía es pasada ampliamente hacia el espacio pericárdico, el catéter teflón es removido. Luego se realiza una pequeña insición sobre la piel con bisturí para disminuir la resistencia que ejerce la piel y celular subcutáneo al paso del catéter pigtail.

Se puede facilitar aún más el paso del catéter con la introducción previa de un dilatador. Estas maniobras facilitan el paso del catéter pigtail a través de los tej idos hacia el espacio pericárdico. Se procede posteriormente al drenaje del líquido mediante aspiraciones repetidas. El catéter pigtail se debe mantener conectado a sistema de aspiración suave continua, tipo Hemosuc, hasta que la producción de líquido pericárdico se encuentre en rango mínimo fisiológico. (Penza, 2017) Las principales complicaciones del procedimiento son el hemopericardio por punción intracardíaca si la aguja es dirigida posteriormente, la laceración del epicardio o del miocardio ventricular, laceración de una arteria o vena coronarias, la laceración de vasos mamarios, fibrilación ventricular, punción del esófago con mediastinitis subsecuente, el neumotorax, hematoma del sitio de punción y la infección de la cavidad pleural o pericárdica.

La tasa de complicaciones reportado por Tsang fue de $1 \%$ de complicaciones mayores (neumotorax) y 3\% de complicaciones menores (punción ventrículo derecho y neumotorax pequeño que no requirieron tratamiento), lo cual se correlaciona con otros reportes. En resumen, el conocimiento de la técnica de pericardiocentesis es fundamental para el adecuado enfrentamiento clínico del derrame pericárdico, sobre todo en situaciones que implican compromiso hemodinámico. Se demuestra que es una técnica eficaz y segura en su implementación. (Penza, 2017) 


\section{Derrame pericárdico diagnóstico y tratamiento}

Vol. 3, núm. 4., (2019)

Jessica María Castro Sánchez; Margareth Lisbeth Sánchez Castro; Cristina Estefanía Colcha

González

\section{Conclusiones.}

El espacio pericárdico, determinado por las capas pericárdicas visceral y parietal, contiene normalmente líquido seroso creando un espacio potencial que rodea el corazón y se distribuye mayormente en los surcos aurículoventricular e interventricular. En base a esto, se define la presencia de derrame pericárdico cuando la cantidad de líquido pericárdico presente en el espacio pericárdico supera el monto considerado normal (aproximadamente $50 \mathrm{~mL}$ ).

Los derrames pericárdicos son de diagnóstico habitual en la práctica clínica ya sea como hallazgo incidental o manifestación de un trastorno cardíaco o sistémico. El espectro de los derrames pericárdicos va desde la presencia de derrames leves asintomáticos hasta el cuadro de taponamiento cardíaco. Los derrames pericárdicos leves (definidos como la suma de espacio libre de ecos en el saco pericárdico anterior y posterior menor a $10 \mathrm{~mm}$ por ecocardiografía) son un hallazgo relativamente frecuente, especialmente en mujeres ancianas.

Los derrames pericárdicos pueden ser, desde el punto de vista de la velocidad de instalación, de lenta acumulación; su progresión puede ser súbita con una rápida evolución al taponamiento cardíaco. En general, el pronóstico depende de la causa y el tamaño del derrame, aunque pequeños derrames no son siempre benignos. El algoritmo diagnóstico de esta enfermedad debe ser guiado por la epidemiología y la presentación clínica para evitar una serie de estudios extensos y a ciegas. Una vez diagnosticada su presencia y gravedad, la tarea más compleja consiste en la evaluación de la etiología.

En países en desarrollo, existe una alta frecuencia de derrames pericárdicos de origen tuberculoso o relacionados con la infección por el virus del VIH o debidos a ambas causas. La 


\section{Derrame pericárdico diagnóstico y tratamiento}

Vol. 3, núm. 4., (2019)

Jessica María Castro Sánchez; Margareth Lisbeth Sánchez Castro; Cristina Estefanía Colcha González

etiologías no idiopática y no virales se asocian con riesgo incrementado de derrame intenso y taponamiento cardíaco, por lo cual la pericardiocentesis es obligatoria. La biopsia pericárdica por pericardioscopia ha demostrado ser útil en el diagnóstico del derrame neoplásica.

a. Electrocardiograma El derrame pericárdico puede causar alteraciones electrocardiográficas no específicas como una reducción en el voltaje del QRS (definido como suma de las ondas $\mathrm{R}+\mathrm{S}$ en $\mathrm{D} 1+\mathrm{D} 2+\mathrm{D} 3<15 \mathrm{~mm}$ ) y un aplanamiento difuso de las ondas T. En presencia de derrame pericárdico grave y taponamiento cardíaco puede observarse alternancia eléctrica (cambios de la morfología y el voltaje del complejo QRS a latidos alternos) debida al movimiento oscilante del corazón dentro de una cavidad con gran volumen de líquido.

b. Radiografía de tórax La radiografía de tórax puede demostrar la presencia de un agrandamiento de la silueta cardíaca con campos pulmonares claros. Este hallazgo, que puede ser fortuito en un examen de rutina en un paciente asintomático, debe plantear la sospecha de derrame pericárdico. El agrandamiento de la silueta cardíaca aparece generalmente cuando se acumulan más de 200-250 mL de líquido en el saco pericárdico. Entre las modalidades diagnósticas, la ecocardiografía es la más frecuentemente utilizada por cuanto permite una valoración semi cuantitativa rápida y de fácil acceso del tamaño del derrame y su efecto hemodinámico

\section{Bibliografía.}

Arias, F. (2010). Paradigmas de la Investigación Científica. España: Editorial: Luces.

Fournier, R. (2017). Molecular analysis of pericardial fluid: a 7-year experience. Review: Eur Heart, 44. 


\section{Derrame pericárdico diagnóstico y tratamiento}

Vol. 3, núm. 4., (2019)

Jessica María Castro Sánchez; Margareth Lisbeth Sánchez Castro; Cristina Estefanía Colcha

González

Keanne, L. (2017). Pediatric Cardiology. 2 a Edición ed. Vol. Capitulo 27, Pericardial Diseases., 11- 66.

Maischa, G. (2017). Guía de Práctica Clínica para el diagnóstico y tratamiento de las enfermedades del pericardio. . Rev Esp Cardiol , 33.

Penza, C. (2017). The use of a polyethelene catheter in the pericardial paracentesis. Review: The Journal Cardiol, 45.

Russ, P. (2016). Critical Heart Disease in Infants and Children. . 2a edición ed. Vol. Cap. 9.'Pericardial Effusion and Tamponade, 22- 45.

Stam, G. (2013). Echocardiographically guided pericardiocentesis: Evolution and state-of-the-art technique. Review: The Journal Medic Cardiology, 55.

$$
\text { (c) }(1)(9)(2)
$$

RECONOCIMIENTO-NOCOMERCIAL-COMPARTIRIGUAL

CC BY-NC-SA

ESTA LICENCIA PERMITE A OTROS ENTREMEZCLAR, AJUSTAR Y CONSTRUIR A PARTIR DE SU OBRA CON FINES NO COMERCIALES, SIEMPRE Y CUANDO LE RECONOZCAN LA AUTORÍA Y SUS NUEVAS CREACIONES ESTÉN BAJO UNA LICENCIA CON LOS MISMOS TÉRMINOS. 